\title{
Prospects and Challenges in Seed Sector Development: Lessons from Eastern Ethiopia
}

\author{
Habtamu Diriba Bula ${ }^{1, *}$, Dandena Gelmesa Soboka², Kemal Kasim Ahmed ${ }^{3}$ \\ ${ }^{1}$ Department of Cooperatives, Haramaya University, Dire Dawa, Ethiopia \\ ${ }^{2}$ School of Plant Sciences, Haramaya University, Dire Dawa, Ethiopia \\ ${ }^{3}$ Department of Rural Development and Agricultural Extension, Haramaya University, Dire Dawa, Ethiopia
}

Email address:

dirbhabtamu@gmail.com (H. D. Bula), dandenagalmesa@gmail.com (D. G. Soboka), kemalkasim@yahoo.com (K. K. Ahmed)

${ }^{*}$ Corresponding author

\section{To cite this article:}

Habtamu Diriba Bula, Dandena Gelmesa Soboka, Kemal Kasim Ahmed. Prospects and Challenges in Seed Sector Development: Lessons from Eastern Ethiopia. European Business \& Management. Vol. 5, No. 4, 2019, pp. 42-54. doi: 10.11648/j.ebm.20190504.11

Received: March 14, 2019; Accepted: May 17, 2019; Published: October 23, 2019

\begin{abstract}
Ethiopian seed system aim to enhance efficiency and satisfy the farmer's seed demand for reliable supply of a range of improved seed varieties of assured quality at an acceptable price. To ensure this goal different actors (operators, supporters, and enablers) are involving in seed value chain. Currently, the seed demand and supply in Ethiopia in general and Hararghe zones in particular is a paradox. Although seed supply does not meet the demand of farmers, significant amount of seed leftover every year at unions and primary cooperatives stores. The objectives of this study were to analyze seed production and utilization trends and assesses institutional and technical capacity of actors across seed value chain in Eastern Ethiopia. The outcome of the assessment revealed that limited availability and access of basic seed for seed production; limited infrastructural and technical capacity of seed producers; fragmented land for seed production; weak internal seed quality inspection; poor post-harvest seed processing and value addition; weak external seed quality inspection and certification services; lack of market information and linkage; poor coordination and collaboration among actors; and natural disasters are some of the key challenges affecting seed business. For seed marketing and distribution the existing conventional seed marketing system in which government plays a dominant role is inefficient to satisfy farmer's seed demand. Our result also revealed that direct seed marketing system cannot address all farmers located over wider agro-ecologies due to geo-location, limited volume, limited infrastructure facilities and diversity. It is recommended that defining clear roles and responsibilities of different actors in the seed value chain and working according to the agreed responsibilities; strengthening institutional and technical capacity of research centers and unions for continues supply of early generation seed and certified seeds, respectively and enforcement of seed regulatory functions to ensure transparency and accountability.
\end{abstract}

Keyword: Cooperative Union, Hararghe Zone, Seed Coordination, Seed Marketing, Seed Production

\section{Introduction}

Quality seed production and supply is one of the key factors to increase crop production and productivity in marginal areas like Hararghe zones in eastern Ethiopia, low agricultural productivity and food insecurity are a critical issue for small holder households. To satisfy the seed demand by smallholder farmers, improved seeds are supplied particularly by public organizations such as public seed enterprises, private seed producers, agricultural research institutes, and universities according to $[1,2]$. However, both public and private seed producers mainly concentrate on a few cereal crops, particularly hybrid maize and bread wheat. Moreover, they supply only a small portion of the total quantity of seed demanded by farmers. Thus, they do not satisfy the diversified seed demand of farmers [3] especially in marginal areas with food security crops. Due to this fact, shortage of adaptable crop varieties and quality seed are among the key challenges affecting agricultural productivity. According to Ethiopian Catholic Church Social and Development Coordinating Office of Harar assessment report in 2011 , roughly $87 \%$ of households in venerable districts of 
Hararghe zones have sold their assets including livestock and land to purchase basic need and food for survival every year. Farmers have too little access to affordable agricultural inputs mainly including quality seeds of locally preferred and adaptable varieties. Poor farmers and women are among these highly vulnerable to this challenge.

Increasing the utilization of seed of improved varieties accompanied with other agricultural inputs and appropriate agronomic practices can dramatically increase Ethiopia's annual crop production. For example studies suggested that adopting improved varieties in an additional quarter of the current crop production area could increase production of maize by over $60 \%$ and self-pollinated crops by over $30 \%$ [4]. In order to improve this situation the operation of different seed system (informal, intermediately, and formal) needs to be strengthened, realizing that each system has its own values and limitations in terms of availability, price, and quality. To a large extent, the quality of seed determines the success of crops in terms of yield (and yield stability) and product quality, and thus its contribution to food security and the value of crop products in the market [5]

Even though farmers have become aware of advantages of seeds of improved varieties through the consolidated efforts of the research and extension systems, seed demand dynamism in the farming community varies due to certain factors. The major factors contributing to the dynamism of seed sector in the zones is due to, limited availability and accessibility of farmers preferred seeds; low farmers knowledge on the merit of quality seed; climate change and drought; price fluctuation of agricultural product including seed; low income level of smallholder farmers; injection of emergency seed; and changing farmers preference to different crop traits. In particular, Hararghe zones seed demand is different in agro-ecology, location, and farmers criteria for seed selection and utilization [4] Due to the unique characteristics of seed demand, seed preference of farmers is still not satisfied by crop types, varieties, timely delivery, and competitive price. To enhance efficiency of Ethiopian seed system government is providing different strategies, policy, and seed laws and supporting development of the sector. Effective and efficient seed production, marketing, and distribution system uses to increase availability, access, and use of improved and quality seed of farmers preferred crops and varieties [4].

On the other hand, seed system in Ethiopia in general and Hararghe particularly represents the entire complex organizational, institutional, and individual operations associated with the development, multiplication, processing, storage, distribution, and marketing of seed in the country. Currently, the demand and supply of Ethiopian seed sector is a paradox. The supply of improved seed rarely fulfilled farmers' needs due to poor demand collection by regional bureaus of agriculture and their respective district level experts and development agents (DAs). Although seed supply does not meet the demand of farmers, significant among of seed leftover every year in unions and primary cooperatives stores [4]. This challenge in-turn poses the business viability of the cooperative unions and primary cooperatives through incurring unnecessary costs related to storage, interest, debt burden, loss in seed viability. Therefore this study was conducted with the objectives to analyze seed production, marketing, and distribution trends; to identify role of different actors and their level of involvement in seed value chain; and to assess institutional and technical capacity of actors operating in seed value chain.

\section{Materials and Methods}

Literature review, focus group discussion, expert elicitation, and field observations were carried out to analyses the current status of seed sector development in eastern Ethiopia. Moreover, organizational documents were reviewed to analyses seed production and marketing performance of the zones.

\subsection{Research Approach}

This study was employed a qualitative research approach to have an in-depth understanding of seed sector performances, complexities and challenges. The research design was nonexperimental approach concerned with the understanding of social phenomenon from the actor's perspective through participation and qualitative analysis [6]. Qualitative research method is used when it is not known what to expect, how to define the issues, or lack of an understanding of why and how populations are impacted. It is characterized by its methods which (in general) generate words, rather than numbers, as data for analysis. Qualitative data was based on empirical investigation and evidence. It can be addressed through qualitative methods such as participant observation, in-depth interviews, and focus group discussion $[5,7,8]$.

The researcher used 'case study' strategies of inquiry to collects open-ended, emerging data with the primary intent of developing themes from the data. Nachmias [9] has pointed out that a case study permits in-depth investigation of the object using a variety of data gathering techniques to produce evidence that leads to understanding of the "case" and answers the research questions. Accordingly, we selected five actors/respondents representing (Zonal and district level agricultural and cooperative promotion offices, Cooperative unions, Seed producer cooperatives, and farmers at eight locations in east and west Hararghe zones.

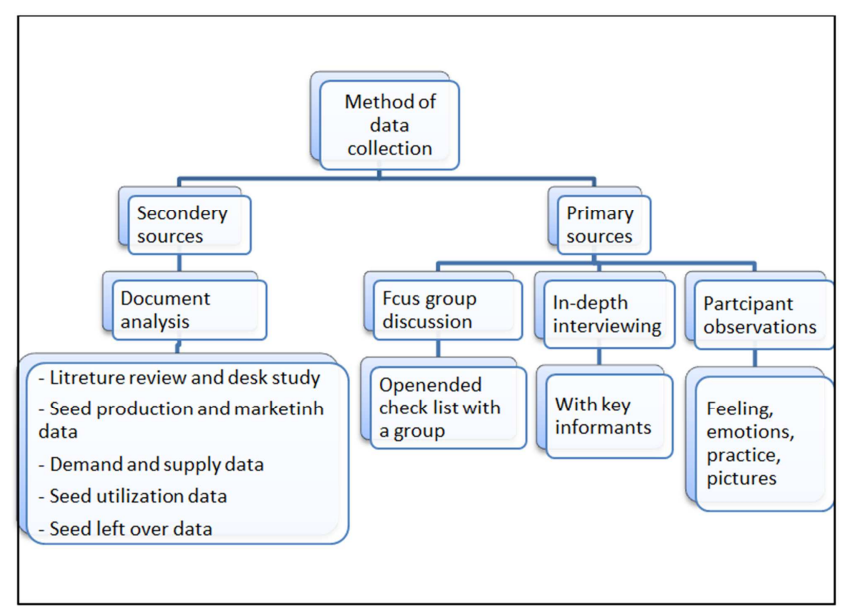

Figure 1. Study approach. 


\subsection{Data Sources and Data Collection Methods}

The study was used both primary and secondary data. The primary data was collected through focus group discussions, interview guide, and personal observations. Focus group discussion provides rich data that is expressed in the words of the respondents and context and it further helping facilitate the understanding of the topic under study. An in-depth interview was conducted with nine technical staff at different level in order to get technical issues and problems of the topic. The Focus Group Discussion was conducted with representative's officials and experts consisting of six to eight respondents. Accordingly a total of 48 respondents participated through Focus Group Discussion methods on data collection. The participants were not limited to particular answers but could give detailed information as per the topic at hand. Participant observation such as their feeling, emotions, motivations, knowledge, views and attitude was captured through formal and informal discussions in order to gain a better understanding of the issues (Figure 1). On the other hand, secondary sources such as organizational documents and reports were reviewed and their data were compared with empirical results (Figure 1). Documents reviewed included: seed production and utilization trend from two zones agricultural offices, three cooperative unions, two zonal cooperative promotion offices, and five seed producer cooperatives; Seed marketing, distribution, and leftover trends in the store of seed distributors (unions and primary cooperatives), and audit report of unions and primary cooperatives.

\subsection{Data Analysis and Interpretation}

Collected data from primary and secondary sources was systematically organised into groups, tables and texts in order to be analyse and evaluated to create usefulness in answering the research questions. Following that, the report was written by a group of researchers whom involved in data collection.

\section{Research Findings}

\subsection{Trends of Seed Production and Utilization}

\subsubsection{Early Generation Seed Production Trend}

Availability and access of quality of early generation seed (EGS) of demanded crop varieties are the key challenges at national in general and Hararghe in particular. Seed producers in Hararghe rarely access basic seed from EGS suppliers due to limited availability of EGS and poor institutional linkage between seed producers and EGS suppliers. The national and regional agricultural research institutes and higher learning intuitions, and private seed companies and public seed enterprises are vested with primary responsibility for production of breeder and prebasic seeds. These institutions include federal and regional agricultural research centers, Oromia seed enterprises, Ethiopia seed enterprise, private seed companies and unions. Seed production field of these organizations concentrated in central part of the country. In the case of Hararghe, three public research centers (Chiro National Sorghum, Fedis, and Mechara and one higher learning institution (Haramaya University) are currently involved in the multiplication and distribution of basic seeds of different crops used by certified seed producer cooperatives and unions.

However, the basic seed production and distribution activities undertaken by these organizations rarely pass through the usual standard for seed inspection and certification since the establishment of regional seed inspection and certification center at Haramaya University via the facilitation of Integrated Seed Sector Development (ISSD) Ethiopia project. Due to this fact these organizations have been producing unknown generation of seeds and distribute as basic seed without getting legal certification by external body (Table 1). This has resulted in limited EGS production capacity and availability for certified seed producers in the region. After the establishment of regional seed certification laboratory center in the region, different awareness creation and capacity building activities were for those organizations to follow the national seed production guideline. Almost all seed under production by these organizations now pass through proper field inspection and certification before seed marketing or distribution.

Other factors that has limiting production and availability of EGS in the region includes natural factors like erratic rainfall and limited infrastructural capacity of EGS producers. Inadequate physical capability (financial, seed cleaning machine, laboratory and storage facility, land, logistics) and human capacity (adequate number of skilled human resource) are negatively affecting production and supply of EGS. Furthermore, limited attention has been given for internal seed quality control by EGS producers from production to processing which resulted in distribution of poor quality seed. For instance, information obtained from FARC showed that annual seed recovery rate of the center is not more than $50 \%$. This is happened due to several factors such as occurrence of drought, lack of irrigation facilities, field contamination and improper postharvest seed processing and storage. While EGS production is considered during off-season using irrigation and reduce the risk of field contamination, bird attack during this season also observed as another critical challenge mentioned. For instance, Chiro National Sorghum Research Center plant sorghum crop for EGS production on 40 ha of land in west Hararghe zone in 2018 completely devastated by bird attack.

To tackle the challenges, EGS production and supply has begun since 2017 by Haramaya University (Community engagement and enterprise development directorate office). This initiative was started through the technical and financial support of ISSD project. In addition to this, ISSD strengthened the capacity of EGS producers (both Haramaya university and research centers) through training, experience sharing and facilitation of linkage to access pre-basic seed. Currently, in 2018 production season, about $161.4 \mathrm{qt}$ (estimate) of certified basic seeds of five crops (maize, sorghum, wheat and common bean) and 1200 qt of potato 
were multiplied and distributed to seed producers (Seed producer cooperatives and Unions) by Haramaya university community engagement directorate office. Other institutions (e.g. Mechara and Fedis research center) still continuing EGS seed multiplication and distribution activities as usual. However, the progress started by the university has showed a promising step toward strengthening EGS multiplication and supply in the region by further strengthening the capacity of EGS producers to ensuring sustainability supply. In this regard, enforcement of seed law and regulation is the burning agenda need to in place among EGS producers.

\subsubsection{Certified Seed Production Trend}

Access to quality seed is a key input and driving force to ensure increased crop productivity and food security of smallholder farmers. Currently, more than 20 organizations are operating as seed production and distribution of different crops such as maize, sorghum, wheat, common bean, chickpea, tef, sesame, potato, finger millet etc. Haramaya university; Fedis, Mechara and Chiro National sorghum research centers; Chercher Oda Bultum Farmers' Cooperative Union, Burka
Galeti Farmers' Cooperative Union, Afren Kelo Farmers' Cooperative Union, and seed producer cooperatives are mentioned among the key operators engaged in seed production and distribution in Hararghe. Trends of seed production volume and crop variety diversity produced and distributed to farmers have showed increasing trends for the past four years. From 2015 to 2018 more than 10 crops of different varieties of seed have produced and distributed to famers. The data collected from seed producers and zone Agriculture office revealed that seed production of different crops is increased almost by five folds in 2018 as compared to seed production status of the region in 2014. Increased demand for quality seed of diverse crop and varieties; production of locally adaptable and farmers preferred varieties; availability and affordability of seeds; involvement of various partners (relevant government offices, development projects, Nongovernmental Organizations (NGOs), university, research centers) that support seed sector development; and establishment of regional seed laboratory are contributed to the overall increased seed production volume in Hararghe.

Table 1. Trends of grain seed production and distribution in west and east Hararghe zones (2015 to 2018) by different organizations.

\begin{tabular}{|c|c|c|c|c|c|c|c|c|c|c|c|}
\hline Year & Maize & Sorghum & Common bean & Wheat & Tef & Sesame & Ground nut & Chickpea & Finger millet & Faba bean & Total \\
\hline 2015 & 2653 & 1075 & 2096 & 325 & 114 & 33.9 & 4.5 & 15 & 0 & 0 & 6287 \\
\hline 2016 & 2977 & 634 & 2392 & 959 & 109 & 1 & 1170 & 122 & 8.33 & 0 & 7318 \\
\hline 2017 & 2089 & 502 & 2645 & 364 & 288 & 130 & 1220 & 111 & 20 & 4.2 & 6275 \\
\hline 2018 & 2494 & 504 & 6030 & 848 & 260 & 110 & 86 & 66.5 & 0 & 0 & 10399 \\
\hline Total & 10214 & 2713 & 13163 & 2495 & 771 & 247 & 358 & 315 & 28.3 & 4.2 & 30308 \\
\hline
\end{tabular}

Even though, there are an increased involvement of operators, crop and diverse varieties and volume of seed production, the efficiency of seed production and processing is affected by many internal and external factors. The assessment survey revealed limited availability and access of basic seed for seed production; limited infrastructural and technical capacity of seed producers; fragmented land for seed production; weak internal seed quality inspection; poor post-harvest seed processing and value addition; weak external seed quality inspection and certification services; lack of market information and linkage; poor coordination and collaboration from supporters and enablers; and natural disasters are some of the key challenges affecting seed business. These challenges resulted in rejection of significant proportion of produced seed. Despite these challenges, comparatively, there are operators who are considerably performing the seed business.

It is evident from table 1 compared to the different crops seed produced or under production in the region, for the last three years 10 crop took about $50 \%$ of the total volume of seed produced. However, other crops seed such as hybrid maize, pulses (except common bean), oilseeds, barley, faba bean, finger millet etc seeds having a niche market are not produced at all or its production is very small. In areas like Hararghe zones supply of diverse seeds of different crop varieties that fulfill farmers farming practices (e.g. intercropping, relay cropping, irrigation based crop production etc) in small pack sizes are very important. The current seeds produced and distributed to farmers by different operators are available with minimum pack size of $50 \mathrm{~kg}$. According to the information obtained during Focus Group Discussion with west Hararghe zone cooperative office experts, this eventually disfavor smallholders farmers, that need small quantity of seed to plant on an average land plot of land which is around 0.125 ha per household.

\subsection{Concepts of Seed Marketing}

Seed marketing should aim to satisfy the farmer's demand for reliable supply of a range of improved seed varieties of assured quality at an acceptable price. However, the difficulties of organizing effective seed delivery systems, especially to small-scale farmers, have often been underestimated in comparison with the attention given to other seed industry activities. Historically, more attention and resources have been devoted to the physical aspects of seed production and storage than to the difficult organizational issues involved in managing sales and distribution. Marketing is one of the most important, yet misunderstood business activities and frequently means different things to different people. To the retailer in the agricultural sector, for example, it is selling seed along with other inputs to the farmer. To the farmer it is simply selling what he produces on his farm. However, whatever the circumstances, a welldefined sequence of events has to take place to promote the product and to put it in the right place, at the right time and at the right price for a sale to be made. Too many people think 
of marketing solely in terms of the advertising and selling of goods, whereas in reality marketing starts long before the goods exist and continues long after they are sold [10]

Market consists of a group of persons or firms on one side, holding a supply of goods, which they want to sell, and on the other, a group of prospective buyers who would like to get goods. Therefore; it is a means to settle the terms relating to exchange of goods or service [11]. Market chain is used to describe the several links that connect all actors and transactions involved in the movement of agricultural goods from the farm to the consumer in the case of agricultural marketing concept. The market channel (inter-organizational network of institutions comprised of agents, wholesalers, and retailers), by performing a variety of distribution tasks, plays a significant role in the flow of products from producers to consumers and on company profitability. Thus, manufacturers are increasingly concerned about the level of performance their channel institutions provide [12].

A supply chain is a network of facilities and distribution options that performs the functions of procurement of materials, transformation of these materials into intermediate and finished products, and the distribution of these finished products to customers [13]. It consists of all stages involved, directly or indirectly, in fulfilling customers appeal. The supply chain not only includes the manufacturer and suppliers, but also transporters, warehouses, retailers, and customers themselves [14]. Therefore, supply chains refer to networks of companies that work together and coordinate their actions to deliver a product to market.

Market efficiency: Clearly, market efficiency is a concept that is controversial and attracts strong views, pro and con, partly because of differences between individuals about what it really means, and partly because it is a core belief that in large part determines how an investor approaches investing. If markets are, in fact, efficient, the market price provides the best estimate of value, and the process of valuation becomes one of justifying the market price. If markets are not efficient, the market price may deviate from the true value, and the process of valuation is directed towards obtaining a reasonable estimate of this value. Those who do valuation well, then, will then be able to make 'higher' returns than other investors, because of their capacity to spot under and overvalued firms. To make these higher returns markets have to correct their mistakes and become efficient over time. Therefore, an efficient market is one where the market price is an unbiased estimate of the true value of the investment [15].

\subsection{Approaches to Seed Marketing}

Varieties of seeds distributed through the public sector are usually under the control of state-run organizations although, where private seed companies are established, they usually have access to these public varieties. Seed distribution may be undertaken by public sector agencies, cooperatives or the private sector or, as is often the case, by more than one of these channels at the same time [10]. Although governments in developing countries have, in general, succeeded in establishing seed legislation as well as seed production and trading activities, government supply objectives are frequently not met and seed stocks remain unsold [10].

This may be because the public sector usually operates passive distribution systems, simply stocking outlets from which the farmer can collect seed but often leaving many outlets unstocked or with the wrong varieties. Such systems are not responsive to the needs of the farmer. However, by introducing a commercial perspective and applying sound management and marketing techniques these passive systems can be transformed into active marketing systems which may prove far more beneficial to the farmer and the supplier. The principle that marketing is about identifying anticipating and satisfying the needs of the farmer, as well as realizing the objectives of the supplier, is fundamental. Even if public sector objectives are not necessarily profit oriented there is no reason why a public organization should not adopt sound management and marketing techniques [10].

\subsection{National Seed Policy}

The role of government should be to create a legislative framework which supports national seed institutions, creates the appropriate economic environment and minimizes government interference in the market. In such circumstances the private sector may be encouraged to play a greater role while guaranteeing the availability of seed of reliable quality to the farmer. Over the past ten years many developing countries have initiated structural adjustment programs in order to correct severe domestic economic problems. An important part of these programs consists of reducing the role of the state in economic activity. One specific area where changes are occurring is in the marketing of agricultural inputs and produce [10].

The pressure for market liberalization is based on the belief that economic performance will be enhanced by involving the private sector and creating competition. However, private business may not always be able to fill the gap left by departing state enterprises. As a result, it may be necessary to combine professionally managed public operations and private enterprise. In privatizing state seed organizations, for example, there is an added risk that private monopolies are created in the place of state monopolies. A steadily increasing number of countries are embracing privatization and seed market liberalization as a solution to the underperformance of public sector seed supply. But no practical improvement in seed supply will result simply by declaring such a policy. Any such change has to be accompanied by a significant shift in attitude and a willingness to implement change [10].

\subsection{Understanding Seed Demand}

Farmers entering the seed enterprise do it for economic reasons and therefore expect economic returns. If the crop fails, a farmer may be less inclined to start again in the next season. There is therefore an element of risk and uncertainty in seed production. The risks begin right from the planning stage where funds are needed for capital inputs such as land, 
machinery, transport and equipment, working capital and the purchase of seed and other raw materials. Several factors are known to influence the overall demand for seed in a given year as well as over the long term. Over-production occurs when actual demand is found to be lower than estimated. This can result from several problems such as seed distribution, movement of farmers to other crops, marketing problems and unrealistic estimates. Over-production may lead to price collapse thus bringing about a lower farm income. Attempting to define future demand is a problematic issue in any seed enterprise. Demand can be estimated as minimum, medium or maximum. Defining demand is more difficult for a new seed enterprise than one that has been in operation previously. Demand forecasting can be based on buyer and seller comments or on surveys conducted in a well-organized system [16].

\subsection{Price-Seed Relationship}

'The higher the price the lower the quantity purchased', especially where there are substitutes available. In the case of seed, farmers can retain the grain of non-hybrid crops, switch from hybrids to non-hybrids or grow different crops. In addition to price, farm income is the major limiting factor affecting what a farmer will spend on inputs. The farmer will have to balance the cost versus the benefit before being persuaded to spend money on inputs such as seed and fertilizers. Unfortunately, seed is often the one item that the farmer believes it is possible to save money on, even though less is usually spent on seed than on any other input.

Marketing and promotional campaigns should be designed to persuade farmers that seed represents good value. Farmers often do not attribute value to seed since, in the case of grain, they think they are producing the very product which they are being sold. Thus it would seem too many farmers that they could just as easily replant their own grain. The importance of price varies from one market to another and between different segments in the same market. For example, nonhybrid seed which the farmer can save will be more price sensitive than hybrid seed. Price will be a more critical factor in marginal farming areas, where spending power is low, but less important where high yields can be obtained and farm produce can be sold profitably. Provided the benefits of the seed are understood, it is other factors, such as the availability of fertilizer and confidence in the produce market, rather than price that dominate the farmer's decision to purchase [16].

\subsection{Characteristics of Conventional Seed Distribution System}

Increased production of agricultural crops depends not only on the development of higher yielding varieties of seeds but also on the efficiency of the systems available to ensure that these seeds reach the farmer on time. Effective seed marketing is thus an essential component of activities to improve food security. No seed production activity can be viable without an adequate marketing and distribution structure. Marketing involves promoting the seed produced by seed producers, and distribution is the physical and logistical exercise of getting the seeds at the right place and the right time. For seed produced by the public seed enterprises, cooperative unions purchase seeds allocated for them based on the set prices from the store of the enterprises. Then the cooperative unions sell to seed users adding transportation and storage costs as well as profit margin [1].

Farmers are often not well informed about the potentially available varieties suitable to their target agro-ecologies and more seriously certain DAs compile seed demand simply from past records. Slow adoption of newly released varieties is another concern, which often gives way for repeated compiling of demand only for known old varieties. The prevailing practices for estimating seed demand from farmers and subsequent seed production targets are sometimes inconsistent and inaccurate, leading to both over and underestimation of demand. The major constraints in seed distribution include limited participation of seed producers in the seed distribution process because the existing system for seed distribution gives lion's share for cooperative unions; hence farmers have no options to choose from different suppliers at a competitive price. Moreover, there is no opportunity as such for seed producers to market the seed they produced. As a result, paradoxically, there is large amount of carry-over seed each year in view of unmet demand. For example, in 2010/11, most hybrid maize seed producers suffered the problem of unsold stocks because of weak marketing and distribution arrangements [1].

Over and above, there is loss of accountability and traceability for seed quality deterioration, including adulteration and weight reduction in route. This is further aggravated by use of multipurpose storage by cooperative unions and lack of suitable storage by primary cooperatives, especially when there is a carry-over. Long distribution chain and shortage of logistics are constraining timely seed delivery to farmers. In other way, the key problems faced by the large-scale parastatal seed organizations were [16] high costs of production and distribution related to consistently low levels of effective demand, and to the high cost of transport from centralized seed production facilities to rural areas; [4] a relatively narrow range of crops/varieties that did not meet smallholder needs; [16] inconsistent seed quality; and [15] escalating financial problems [1].

\subsubsection{Seed Marketing}

Seed demand and supply in Hararghe is paradox. Farmers are complaining lack of access to quality seed at one hand and leftover problem on the other hand. Increased availability of locally adaptable quality seed and farmers awareness on the merits of quality seed determines level of farmer's seed use and satisfaction. The information gathered during Focus Group Discussions from different actors and complied data (Table 1) revealed that both seed supply and utilization have showed increasing trends for the last four years. Comparing the two zones greater proportion of seed was supplied in west Hararghe zone from other sources (outside the region) in the 
past four years. Similarly, the proportion of leftover seed $(6.21 \%, 3.08 \%, 22.06 \%$ and $36.37 \%)$ in $2015,2016,2017$ and 2018 , respectively in west Hararghe was much higher as compared to leftover seed in east Hararghe. The main factors contributing to leftover seed in general includes inaccurate seed demand collection (both under and over estimation); limited availability of preferred varieties; variation in seed replacement rate of farmers; weak commitment and accountability of ICU; poor extension services about the merits of quality seed and new varieties; untimely supply of seed; high prices for some seeds due to unnecessary overhead cost; supply of poor quality seed; change in farmers demand due to drought or emergency seed distribution; and poor infrastructure facilities (road, store) are mentioned during the Focus Group Discussion with participants at different places. Lack of proper inventory for leftover seed and poor quality test mechanisms by responsible body for leftover seed are increasing the burden and risk of principal and repayment of interest on unions and primary cooperatives.

Seed leftover of last year distributed to farmers in the following year by checking only germination percentage at either woreda or zone level Agriculture office. According to zone Agriculture office in west Hararghe zone, samples of leftover seed are collected from union and primary cooperatives stores and germination percentage is checked by expert assigned from Agriculture office. The result of germination percentage notified officially to union either to distribute or reject leftover seed. The primary cooperatives and Chercher Oda Bultum union at Oda Bultum woreda confirmed that germination percentage is the only parameters used as quality assurance by the zone Agriculture office to distribute leftover seed. Similarly, the Chercher Oda Bultum union also checks germination percentage for leftover seed to cross check with the result of Agriculture office. On the other hand, according to the information obtained from east Hararghe zone Agriculture office, leftover seed germination percentage is checked by woreda level Agriculture office experts and the official results informed to unions either to distribute or reject the seed. However, union complaining that there is no official letter received from woreda or zone
Agriculture office either to distribute or reject leftover seed. According to the information obtained from union, Agriculture office hesitates to notify the decision of the result by letter. Either personal contact or phone call mainly used to notify the result. Because of this the union has lack confidence and guarantee to distribute leftover seed. There is also free rider interest by some persons in this regard who prefer to supply seed from other sources rather than using leftover seed.

Generally summarizing the empirical finding indicated above, experts and representatives of Agriculture office believe germination percentage as the only parameters to assure seed quality standard. The study revealed that this could pose a big risk for seed users since physical germination parameter is unacceptable standard to assure seed quality. The procedure for seed sampling and quality testing for leftover seed is not following the standard set by national seed quality inspection and approval. It is also not the role of Agriculture office to collect samples from leftover seed and inspect seed quality. Lack of awareness by BoA, unions and cooperative offices about the role of seed quality control and certification laboratory center established at Haramaya University to provide the service is observed. In addition, the study explored there is lack of knowledge and awareness about seed quality assurance and seed law among seed actors.

According to west Hararghe zone Agriculture office, regarding accountability for seed leftover, the respondent confirmed all actors who involved in the seed system in the zones especially Agriculture office, Cooperative, unions, primary cooperatives, ICU and administration are responsible and accountable for seed leftover. Lack of accountability created all this problems of seed distribution. East Hararghe zones Agriculture office hesitate to mention the responsible body for seed leftover. The audit report of Chercher Oda Bultum and Afran Kallo unions for instance indicated that $154,354,264$ and $221,008,553$ birr liability respectively is accounted for input (seed and fertilizer). This is true also for almost all primary cooperatives engaged in input distribution.

Table 2. Seed demand, supply and distribution trends in west Hararghe.

\begin{tabular}{lllllll}
\hline Year & Amount demanded (qt) & Amount supplied (qt) & Demand Meet (\%) & Seed distributed (qt) & Leftover seed (qt) & \%o of leftover \\
\hline 2015 & 8763.22 & 8763.22 & 100.00 & 7084.22 & 6.31 \\
2016 & 24463.0 & 35894.61 & 146.73 & 34820.86 & 34.00 \\
2017 & 23591.73 & 12360.00 & 52.39 & 10126.25 & 1073.75 \\
2018 & 9002.9 & 8962.87 & 99.56 & 6572.70 & 2233.75 \\
\hline
\end{tabular}

Table 3. Seed demand, supply and distribution trends in east Hararghe (Chercher Oda bultum Union).

\begin{tabular}{llll}
\hline Year & Amount supplied (qt) & Seed distributed (qt) & Leftover seed (qt) \\
\hline 2015 & 4700 & 4621.125 & 79.375 \\
2016 & 16894.38 & 16794.38 & 99.62 \\
2017 & 8856.125 & 8694.25 & 161.875 \\
2018 & 4834.43 & 4717.625 & 116.375 \\
\hline
\end{tabular}

Regarding farmers' satisfaction; seed provision at right time improved somehow, but quality problem and inappropriate variety demand by farmers continue to be a challenge. There is no agency that collects farmers' feedback. However, pioneer company started collected feedback for seed they deployed. Despite limited seed extension, farmers 
aware the importance of using quality seed.

\subsubsection{Seed Demand Assessment and Allocation}

To recognize success in any business activity, customer demand identification should be the first step. This step is a base for satisfying customer, retaining more market share, and generating high revenue. Having sufficient information on customer preference enable the business to decide what type of product to produce, what kind of value should be added to the product, where the product has to be deliver, and how the purchasing power of customer. Similarly speaking, seed production, marketing, and distribution are part of business activities and the science procedure they should follow is also similar with any business type. Before deciding production seed producers should know their customer actual problem and need in all dimensions (type of crops, quality and quantity, varieties, agro-ecology, delivery time and place, purchasing power).

This study revealed that, the seed demand assessment has conducted by third parties i.e. Agriculture office. Bureau of agriculture collect or estimate seed demand of farmers through development agent at local level. The demand collected by development agents' compiled and approved at woreda level by ICU committee (Input Coordination Unit) involving bureau of agriculture, cooperative agency, administration office, and finance and economic development office. The demand data compiled at woreda level again refined at zonal level by the same committee at zone level and report to the regional Bureau of Agriculture and Natural Resource. This process is to facilitate seed allocation at regional level to all zones and woredas of the region. After the demand data summarized at regional level allocation started. Then, source of seed is identified by regional Agriculture office to facilitate allocation according to the demand data requested. During source identification, the leftover seed not considered by east Hararghe Agriculture office, while west Hararghe zone Agriculture office considers to include in current allocation. After this process allocation take place based on available seed and to some extent based on demand collected.

The existing seed demand collection and allocation, does not meet the actual need of farmers. This is due to various challenges such as, lack of commitment by DAs to collect actual demand; estimating demand based on past year trends in the office; politicizing demand collected by DAs at woreda level for the sake of getting recognition; limited information by farmers and DAs on the existence of new crop varieties adaptable to the areas; Limited time given for DAs for demand collection; Lack of joint planning and joint demand collection; non-professional workload and additional assignment; flexibility of farmers demand due to climate change and distribution of emergency seed. Moreover, lack of focus and attention from concerned body at different level; lack of monitoring and evaluation from Agriculture Office; lack of support and incentive for DAs; lack of means of verification at kebele, woreda and zone level are another challenges for demand collection. The other challenges of demand assessment was lack of focus and attention from concerned body at different level; lack of monitoring and evaluation from Agricultural office; lack of support and incentive for DAs; nature of the work which is tiresome; lack of means of verification at kebele, woreda and zone level.

The Focus Group Discussion said there is inaccurate demand assessment. This is consequently resulted in; high Seed leftover; and high debt registered on unions and primary cooperatives. The debt at country level is estimated at 13 billion birr. The leftover was checked for germination by woreda BoA and sold for farmers in the following year. In addition, allocation processes by Agriculture office mainly focus on types of crops and volume of seed with little attention on variety of crops requested by farmers at specific agro-ecology. The bureaus simply match the existing variety at source irrespective of the requested varieties. This is due to the reality that either requested varieties lacks at the source or lack of accountability. As a result, farmers are not getting required seed in quality, quantity, availability, variety, and place and at affordable price. Unions and primary cooperatives are not satisfying demand of farmers, they are taking unnecessary risk and costs due to seed leftover and debt burdens. Farmers are complaining unions and primary cooperatives since they supplier of seed which is other than their preference and at low quality standards. Due to this seed distributers are losing both trust and facing bankrupt in their financial performances.

\subsubsection{Seed Supply and Distribution}

In the study area seed marketing and distribution is dominated by conventional or existing seed marketing system in which government role is dominant. As we indicated in previous section, seed demand collection and allocation at regional level is the role of government through Agriculture office. Similarly, government played significant role in seed supply and distribution through Cooperative Agency. The cooperative agency this role by facilitating seed purchases process from seed source through loan acquired from National Bank. Following that, the agency order cooperative unions to transport the purchased seed to identified woredas and sites. Then, union distributes the seed to potential primary cooperatives so as to sell on cash or in credit to individual farmers. In addition cooperative agency facilitates credit collection from seed sold and repayments to National bank. In this process, the actual work primary cooperatives collect credit from farmers and deposit to the bank account of respective union and the union transfer the deposited money to account number of national bank indicated by cooperative agency in the letter.

In this marketing and distribution process cooperative unions and primary cooperatives play the role as operator. However, it is revealed that the union and primary cooperative do not have a power to decide on demand data, seed source, and allocation. Unions and primary cooperative are responsible for sale, cash collection, store management for leftover, repayment of principal and interest for debt.

Under this seed supply, marketing, and distribution, unions 
and primary cooperatives have no sufficient information on seed demand, no mandate to negotiate on loan agreement with financial institution, to decide on source of seed, price decision, to decide type of crops and varieties, volume of seed, and quality of seed. Irrespective of this work that are conducted by third parties, the unions and primary cooperatives are responsible for seed leftover, quality problem, credit repayment, and interest payment. Through unions and primary cooperatives were ordered by cooperative agency to play this role; finally they are accountable problems and risks encountered the process of seed marketing and distribution.

\subsubsection{Seed Marketing Approaches}

i. Conventional seed marketing

Conventional seed distribution system is an existing system in which government play considerable role in seed distribution and marketing system. In this system seed demand collection and seed allocation is the role of government through Agriculture office. Facilitation in seed distribution and marketing is also role of government using cooperative agency. Credit or finance facilitation is the role of government by cooperative agency. The role of seed producers is only producing what they want and report to Agriculture office. The role of unions and primary cooperatives is only supplying and distributing allocated seed to farmers. Although seed supplies without their plan, have no information whether the seed demanded by farmer they are responsible for seed leftover, storage management, lost, credit, and other related costs.

According to the focus group discussion, in this system unions and primary cooperatives are not benefited and taking unnecessary risk and costs associated to the process. The study shows that the level of farmer's satisfaction is very low due to low seed quality, type, and price. The process is long, complex, time consuming and inefficient. Seed producer's such as seed companies and seed enterprises has in demand collection, distribution and marketing. As a result through the existing conventional seed system the seed business is not demand driven and market oriented.

ii. Direct seed marketing

Direct seed marketing is the process in which producers take full responsibility for seed production, marketing, and distribution. This system simplifies the long chain in conventional seed marketing system. Seed producers and users have direct relationship or through their agent. The system enables seed producer to identify the specific need of seed users and seed production and distribution is based on demand. Since seed producers and users have direct relationship, producers can easily collect feedback from seed user and improve their performance based on customers demand and preferences. DIRECT SEED MARKETING system has also advantage to farmers due to the reality that different producer's come up with different crops and varieties and enable farmers to have an alternative in crops, varieties, qualities, price and others. The models enhance competition among producers and enforce them to improve their product portfolio, quality, price and etc. This marketing approach reduces the role of government in seed marketing and distribution, and enhances the role of seed producers.

The piloting work of Direct Seed Marketing started in 2012 by ISSD project and currently, the coverage has reached more than 228 woredas in four region states (Oromia, Amhara, SNNPR and Tigray) of Ethiopia. According to ATA August 2018 press release, the system has saved more than one billion Ethiopian Birr that the regional government has been used for seed distribution in conventional seed system. In Hararghe zones piloting Direct Seed Marketing was started in 2018 in seven woredas including Haramaya, Bedeno, Gurawa, Meta, Tullo, Mesela, and Oda Bultum. The Focus Group Discussion appreciates Direct Seed Marketing success to some extent in Hararghe. The information obtained from zonal office of Agriculture office and cooperative agency revealed that the system was introduced to overcome challenges encountered in the existing conventional seed system. They confirmed that the Direct Seed Marketing is shows betters success than conventional seed marketing through linking producers and seed users to interact directly/through agent; reduces long-term transaction cost; reduces bureaucratic procedures;; ensures high accountability and responsibility; delivers seed at the right time; reduce government involvement and enhanced role of operator in seed marketing and distribution.

However, the assessment result showed that there are challenges encountered during implementation of Direct Seed Marketing in the two zones. These challenges are lack of awareness about modalities and approach of Direct Seed Marketing implementation among actors; involvement of illegal grain traders as agents of producers; different interests of individual to continue conventional seed system; lack of competitors and variety portfolio; conflict of interest among Agriculture office and cooperative agency. In addition, lack of prior information about the context; inappropriate planning and poor infrastructural facilities has resulted in under or oversupply of seed in some woreda affected the success of the model as planned. The Focus Group Discussion said that, farmers also complained for seed dropped at woreda town irrespective of the assumption that seed should delivered at accessible sites that expose farmers for additional costs like transportation.

It is confirmed that, Agriculture office and cooperative agency mis-understood the modalities of Direct Seed Marketing implementation of selected woredas should be supplied by a single supplier who agreed to supply seed directly/through the agent without a competition. This put a total embargo on Seed producer cooperatives, union or primary cooperative in the region to enter into Direct Seed Marketing competition or seed supply through conventional approach at selected Direct Seed Marketing woredas. As a result, Direct Seed Marketing failed to deliver required seed in quality and quantity.

\subsection{Performance and Coordination of Actors in Seed Sector}

\subsubsection{Institutional and Technical Capacities of Actors}

Institutional and technical capacities of actors are 
necessary to play significant role for better performances of seed sector. The study showed that for quality seed production and certification, the technical and infrastructural capacity of actors in Hararghe is limited due to various challenges. The Focus Group Discussion result explored various challenges observed both at quality control and certification center and producers level are limited knowledge and awareness of seed producers; lack of seed infrastructure and value addition (standard warehouse, seed processing technologies); lack of planning and data management among seed producers; lack of accessing certificate of competence (CoC) to be qualified for certification requirement; and lack of centers human and financial resources, and logistics facilities. Except nine primary seed producers' cooperatives and one union all seed producers in Hararghe do not have legal license $(\mathrm{CoC})$ for seed production and distribution including the research centers (Fadis, Mechara and Chiro national sorghum) and Haramaya University.

It was observed that, limited technical challenges related with quality seed production and processing by operators includes poor crop rotation, poor field preparation, improper field isolation, roughing off, limited field inspection, seed cleaning, grading and certification. In most cases seed produced by Haramaya University and regional research center (FARC and McARC) are distributing different crops seed without official certification. Internal seed quality inspection or regulation for all producers is not well organized to make the decision for proper seed inspection. Technical, financial, human power limitation as well as bad perception about the cooperative by Agriculture office and cooperative offices is some of the reasons mentioned. Limited capacities of Seed producer cooperatives and unions to collect seed on time and processing for laboratory analysis certification.

\subsubsection{Coordination and Linkage Among Actors}

Coordination and linkage among actors in seed value chain plays a very crucial role to enhance efficiency of seed production and marketing. Multi-stakeholders should participate as operators, supporters and enablers to play different roles in the chain. Despite this reality, the study revealed weak linkage and coordination among actors in seed sector. to produce quality seed at required standard. Seed producers (SPC, unions, universities, and ARCs) needs to play operation role of production and processing, supporters (Agriculture office, SQCCE, cooperative agency, and development projects) expected to play role of providing technical support in agronomic practice, field inspection and laboratory analysis for quality control, facilitate supply of input for seed production. Enabling environment is also another requirement for seed production such as seed law, seed regulation, and land policy. However the result of the study shows that coordination among these actors is weak in production process. In addition except Babile woreda in East Hararghe zone there is no technical support by Agriculture office to seed producers. Support from cooperative agency in planning and organizational management is not at expected level.

For seed marketing and distribution operators are unions and primary cooperatives; supporters Agriculture office, cooperative agency, financial institution; enabling environment seed law and regulations, cooperative law, and pricing policy. According to the result of this study Agriculture office play the role of demand collection, compile the demand data and send request to regional Agriculture office for seed allocation, while cooperative agency play the role of facilitation in seed marketing, distribution, and finance for seed production. In implementing these different activities coordination among these actors is weak. In requisition of seed demand of the zone Agriculture office do not consider seed producer in the region due to low recognition and late certification. Experts from Agriculture office and local farmers are not trust locally produced and certified seed due to low attitude and awareness. Late seed certification is due to low technical support of Agriculture office to prepare seed at required standard for laboratory sample taking. In some cases ignore seed leftover in allocation and weak communication among unions, primary cooperatives, SOCs, and Agriculture office to have actual data of seed leftover seed production in the zones. There is no joint planning, demand collection, feedback assessment, seed allocation, and seed distribution among and between actors. In addition lack of good governance, poor business management practices of Seed producer cooperatives at various levels are external factors those negatively competitiveness Seed producer cooperatives.

Due to all this problems huge amount of seed leftover was observed at different stores of unions and primary cooperatives in the zones. On the other hand seed demand of farmers satisfied in different woredas. The viability and profitability of unions and Seed producer cooperatives are under risk conduction due to debit overload and leftover problem.

Financial institutions providing agricultural loans, requires evidence of collateral and matching funds and charges high interest rate. As a result, Seed producer cooperatives and farmers cannot afford to establish modern, well-equipped drying and storage facilities.

Table 4. Analysis of financial structure of Seed producer cooperatives.

\begin{tabular}{|c|c|c|c|}
\hline Name of Seed producer cooperatives and unions & Liability & Owners' equity & Debt-equity ratio \\
\hline Jaliissii Midhagduu & 464,222 & 91,255 & 5.09 \\
\hline Misooma guddina & 346,525 & 642,847 & 0.54 \\
\hline Jiruu Jalaala & 141,582 & 170,196 & 0.83 \\
\hline Jaliisii Abdi Gudina & 815 & 9,700 & 0.08 \\
\hline
\end{tabular}




\begin{tabular}{llll}
\hline Name of Seed producer cooperatives and unions & Liability & Owners' equity & Debt-equity ratio \\
\hline Abdii Jalaala & 32,422 & 249,604 & 0.13 \\
Biiliisaa & 58,710 & 245,818 & 0.24 \\
Burqaa Gamachuu & 231,352 & 299,139 & 0.77 \\
Rakkata Fuuraa & 11,876 & 72,696 & 0.16 \\
Caffee Guddinaa & 32,067 & 63,628 & 0.50 \\
Daro Goraa & $1,237,426$ & $1,174,147$ & 13.02 \\
Milkesa Lafto Goobaa & $1,086,396$ & 83,460 & 0.53 \\
Odaa Maddaa & $1,082,373$ & $2,040,722$ & 7.57 \\
Awubera & $9,092,276$ & $1,200,599$ & 6.55 \\
Jalela gudina & $1,096,392$ & 3.44 \\
Medajeneta & $1,331,575$ & 0.13 \\
Lelise ifadin & 67,674 & 386,407 & 4.47 \\
Haji faji & $1,700,038$ & 541,303 & 2.70 \\
Oda ifa & 203,163 & 380,670 & 0.95 \\
Melka buba & $1,419,557$ & 75,379 & 2.42 \\
Lega hamaressa & 196,959 & $1,495,416$ & 3.45 \\
Efa egu & $1,560,474$ & 81,423 & 7.34 \\
Tofik & 568,850 & 452,235 & 0.14 \\
Bala bukis & 35,380 & 77,502 & 0.67 \\
Rare hora & 260,038 & 245,420 & 7.14 \\
Berisa awsherif & 265,189 & 388,617 & 0.06 \\
Bishan babile & 146,209 & 37,135 & 3.46 \\
Chercher Oda Bultum Farmers' Cooperative union & $154,354,264$ & $2,644,835$ & 2.19 \\
Burka Galeti Farmers' Cooperative Union & $59,499,222$ & $44,674,021$ & 7.16 \\
Afren Kelo Farmers' Cooperative Union & $221,008,553$ & $27,122,838$ & 3.94 \\
Total & $457,531,579$ & $30,864,187$ & \\
\hline
\end{tabular}

Due to huge amount of seed leftover was observed at different stores of unions and primary cooperatives in the zones. Primary cooperative and unions enforced to supply and distribute seed and fertilizers on account to farmers without legal contractual agreements for long periods. This situation makes difficulty to collect the debt and overload necessary debt burden on primary cooperatives and unions. As the result the debt to equity ratio shows 3.94 . This result indicates the debt burden is 3.94 per each birr in owned equity and the financial structure of unions and primary cooperatives is very weak.

\subsubsection{Views, Perception and Practices of Actors}

Cooperative is autonomous association of persons united voluntarily to meet their common economic, social and cultural needs and aspirations through a jointly-owned and democratically-controlled enterprise. This definition indicates that cooperative is primarily organizes to solve socio-economic problem of members. As social service cooperative involves in community development activities and in doing that it makes reasonable profit which realizes sustainable development of the organization and ensure sustainability of the business. As an enterprise cooperative involves in any business activity (production, processing, service, and marketing) to make profit and then to solve economic problem of members.

In Ethiopia cooperatives are established in line of International Cooperative Alliance (ICA) principles and values. In addition to these principles and values proclamation declared for establishment of cooperatives and legal framework desired for cooperative regulation in the country. Based on this proclamation, cooperative established at different level in Ethiopia and actively involving in economic and social development activities. In addition to different business and social development activities they are also playing significant role in seed distribution and marketing. In the study area also cooperatives are acting as business enterprise and social service organizations. They are playing considerable role in agricultural input supply, seed distribution and marketing activities. However in both East and West Hararghe zones different stakeholders have different view on using cooperative as a tool in seed distribution

i. View of Agriculture office and government administrative

As the result of Focus Group Discussion indicated in Hararghe zones, according to the point of view of Agriculture office and government administrative, cooperatives are an organization established by government to provide social service to the community in distributing seed and other agricultural inputs at low or even on margin. To this effect primary cooperatives and unions are influenced to involve in this activities without their own plan and without considering cost-benefit of the activity. This view is against the primary objective, principles, and cooperative laws. The main target of these stakeholders is delivering the supplied seed to farmer.

As the result of focus group discussion indicates this action take place through influencing cooperative agency and cooperative agency enforce cooperatives to provide the service. Giving the mandate to cooperative is an opportunity if they play the role by their own plan and considering costbenefit of the activities. But the problem indicated here is related to implementation process. If cooperatives know actual demand of farmers and supply based on the actual demand it is an opportunity to provide social service and at the same time make profit. The problems identified in this 
process are low awareness of stakeholders on cooperative law and principle, need to give immediate solution to the community problem in supplying seed to farmers, and assuming cooperatives are easiest way to rich all community in short period of time.

ii. View of cooperative agency

According to the result of the Focus Group Discussion, the point of view of cooperative agencies cooperatives are organization established to solve socio-economic problem of members. According to their view cooperative should generate margin in their social and economic activities to ensure sustainable development realize objective of its establishment. However since they are part of government structure they cannot against the view of Agriculture office and government administrative. Therefore as the result of focus group discussion indicates cooperative agencies are trying to create awareness to stakeholders on cooperative laws and principles.

\subsubsection{Actors Awareness on Cooperative and Seed Laws and Enforcement}

Seed law and regulation designed and in place to ensure quality seed production, processing, marketing and distribution in Ethiopia. This law and regulation is to ensure production and marketing of seed at required standard and to avoid illegal seed production and marketing which against production and productivity of agriculture.

In Hararghe, there is lack of awareness of actors on seed regulation and proclamations from zone to kebele level. The problems are observed both at individual and institutional level. As a result many actors are violating seed laws and illegal seed marketing became normal in the region. The Input Coordination Unit (ICU) committee that have established at various level including zone, woreda and kebele level was not abide by input (seed, fertilizer) law and regulation. This ICU established to make sure that demand driven agricultural input including seed are available in quantity and quality at the right place and time to smallholder farmers. Despite this, finding suggested that seed demand assessment has got many problems including reporting of inappropriate demand in terms of amount, variety, agroecology, timeliness, price, and others. As a result seed leftover became common for long years at union and primary cooperative store. The committees are just politicizing false reporting of quality seed coverage. Finding shows that there are many incidences where primary cooperatives resist seed that are not relevant to their agro-ecology and not in line with their demand. In that cases zone administration, Agriculture office and zone cooperative agency forced primary cooperatives to accept the seed. This finally resulted in the seed leftover at cooperatives and union. The violation of this seed laws are due limited awareness of actors on seed law, absence of harmonization of seed laws at lower level; and lack of accountability and commitment to ensure implementation of seed law.

Seed leftover of last year distributed to farmers in the following year by checking only germination percentage at either woreda or zone level. The Agriculture office checks only germination of seed leftover to distribute in the following year. Experts and representatives of Agriculture office believe germination as the only parameters to assure seed quality standard. The researcher of this study observed this could pose a big risk for seed users since physical germination parameters are unacceptable standard to assure seed quality standard. This study confirmed that there is lack of knowledge and awareness about seed quality assurance and seed law among seed actors. The actors even do not know the existence of HU-seed quality control and certification center. There are also lack of awareness among ISSD project partners regarding seed laws and regulations. Training and awareness creation on seed proclamation is put as recommendation by the respondents.

\subsubsection{Actors and Stakeholders Motives and Commitment}

Agriculture office main objectives and motives are to increase production and productivities of agriculture. This objective could be realized through adopting agricultural technologies. Improved and quality seed is one of the key inputs among agricultural technology which can enhance productivity of agriculture. Increasing availability and access to improved and quality seed could be realized through effective and efficient seed production and marketing systems. For quality seed production the role of Agriculture office is providing technical support to seed producers through development agent and woreda experts. However in Hararghe zones except Babile woreda the commitment of Agriculture office to support seed producers in seed production is low.

In seed marketing and distribution the main role of Agriculture office is creating demand to improved and quality seed, seed demand collection, compiling seed leftover data, compiling the zone seed production data, and facilitate for seed allocation process. However the reality observed during Focus Group Discussion is that the office except estimating seed demand of farmers the commitment of the office for actual demand collection, seed demand creation, compiling seed leftover and the zone seed production data to consider for seed allocation is low. The main motives and objective of cooperative agency is strengthening cooperative organizations to solve socio-economic problems of members. Cooperatives could solve socio economic problem of members through involving in economic activities such as production, processing, and marketing goods and service to the community at reasonable price and generating profit from the business. Seed production, processing, and marketing are among the main economic activities of cooperatives in Hararghe zones. According to the result of Focus Group Discussion and motives of cooperative agency, to achieve objectives of their establishment cooperative should controlled democratically and autonomous. However for agricultural input marketing and distribution including seeds cooperatives are not free from external influence such as cooperative agency. Cooperative agency influences them due to influence from Agriculture office, and government 
administrative. The collaboration and commitment of Input Coordination Unit (ICU) is also weak in collecting and approving actual seed demand of farmers.

Key partiers supporting seed producers are Universities, ARCs, and unions. Main motives of universities and ARCs is transferring improved technologies including improved seed to farmers so as to increase production and productivity of agriculture, increase income of households, and changing livelihood of stallholder farmers. Cooperatives are a best tool to address more farmers within short period of time. Therefore Haramaya University, Oda Bultu University, and Fedis ARC are supporting Seed producer cooperatives in collaboration with ISSD. However to address the objectives the budget and logistic facilities related to the support is limited to grant provided by ISSD. Low commitment of experts to support Seed producer cooperatives due to lack of incentive is also another problem observed during the assessment.

\section{Conclusion and Recommendation}

To ensure goal of enhancing efficiency of seed system and satisfy farmer's seed demand different actors (operators, supporters and enablers) are involving in seed value chain. Currently, the seed demand and supply of Ethiopian in general and Hararghe zones in particular is a paradox. Although seed supply does not meet the demand of farmers, significant amount of seed leftover every year at unions and primary cooperatives stores.

Regarding seed production Haramaya University and Agricultural research centers (Fedis, Mechara, and Chiro National Sorghum research) are involving in certified seed production. However re-multiplied seed of unknown generation, lack of quality assurance (certification), poor in quality, limited infrastructural capacity, and natural factors like erratic rainfall are challenges affecting the success of EGS supply in Hararghe. For certified seed production Farmers' Cooperative unions (Chercher Oda Bultum, Burka Galeti, and Afren Kelo) and seed producer cooperatives are involving in certified seed production. Limited technical capacity, limited infrastructural capacity, limited access to EGS with required crops varieties are among challenges observed for certified seed production.

The conventional seed marketing and distribution system is not efficient to supply seeds with required variety, at required time, with required quality, and at affordable price. In this seed marketing system government play dominant role of demand collection, source identification, and allocation. The system is complex, long chain, time consuming abs inefficient. The role of unions and primary cooperatives limited to seed supply and distribution. The Direct Seed Marketing system also cannot address all woredas of the zone due to geo-location, limited volume, and diversity. Multiple actors play different role in seed value chain. However weak coordination and linkage among actors in seed value is main challenge observed to enhance efficiency of the seed sector. Role operator, supporter and enablers are not well identified for actors. Lack of accountability and responsibility is also another challenge identified for better coordination of actors in seed value chain.

\section{References}

[1] AmsaluAyana, AshinieBogale, AbdoWoyema, (2011). Analysis of Seed System in Oromia: Opportunities for Improvement, Finfinne.

[2] Thijssen, M., Z. Bishaw, A. Beshir, and W. S. De Boef (2008). Farmers, seeds and varieties: Supporting informal seed supply in Ethiopia. Wageningen, The Netherlands: Wageningen International.

[3] Bishaw, Z. and N. Louwaars, (2012). Evolution of seed policy and strategies and implications for Ethiopian seed systems development, 31-60.

[4] Alemu, Dawit, (2014). Analysis of Post-harvest Loss Estimates and Policy Processes. Ethiopian Institute of Agricultural Research (EIAR).

[5] Louwaars and De Boef, 2012). Integrated Seed Sector Development in Africa: A Basis for Seed Policy and Law. Journal of Crop Improvement, 27: 2.

[6] Cohen, Louis, et al, (2007). Research methods in education (6th ed.).

[7] Kothari, C. R. (1990). Research Methodology: Methods and Techniques Wishwa. Prakashan, New Delhi.

[8] Mack, et al. (2005). Qualitative Research Methods Overview. In: Qualitative Research Methods: A Data Collector's Field Guide. North Carolina, Family Health International, 1-12.

[9] Nachmias C Nachmias D, (1992). Research Methods $m$ the Social 450 Sciences from faculty of 101 at University Professor. Dr.. Moestopo (Religion).

[10] FAO corporate document repository 2007

[11] Sontakki C. N. and R. G. Deshpandee, (2003). Principle of Marketing. Kalyani Publishers, New Delhi-Ludhiana.

[12] Rosen bloom, B., (1999). Marketing Channels: A Management View. Hinsdale, IL: Dryden Press.

[13] Ganeshan, Ram, and Terry P. Harrison, (1995). An Introduction to Supply Chain Management, Department of Management Sciences and Information Systems, 303 Beam Business Building, Penn State University, University Park, PA.

[14] Chopra, Sunil, and Peter Meindl, (2001). Supply Chain Management: Strategy, Planning, and Operations, Upper Saddle River, NJ: Prentice-Hall, Inc.

[15] CFABI (Center for Agriculture and Bioscience International), (1997). Agro-Food Marketing. CABI Publishing, Willing Ford, Oxon. Ox10 8DE. UK.

[16] AbebeAtilaw and LijalemKorbu, (2013). Recent development in seed systems of Ethiopia, 2013. Ethiopian Institute of Agriculture Research, Debrezeit, Ethiopia. 